\title{
To the question of the value of sharpening of the corners of working bodies of agricultural machines. Justification. Influence on the quality of work
}

\author{
Sergey $V$. Belousov* \\ Kuban State Agrarian University named after I.T.Trubilin, Krasnodar, Russian Federation
}

\begin{abstract}
The paper highlights the influence of the angle of sharpening of tillage working bodies and their theoretical justification. The work is of a research nature, expressed in the fact that a theoretical analysis of the method of determining the angle of sharpening of tillage working bodies by their degree of wear is given. The type of construction is proposed and described. As a result of this work, the angle of sharpening of the working bodies and the influence of wear on the traction resistance of the blade plough are theoretically proved. The conclusions present the main results achieved so far.
\end{abstract}

Designing of tillage units and machines is a complex technological and production process. Of the entire complex of field operations, the most energy-intensive process is ploughing. According to long-term data from leading scientists and research institutes, up to $35-40 \%$ of energy and $22-30 \%$ of labor costs are required to perform dump ploughing. More and more metal-intensive and technological machines and units have recently appeared for tillage. So, in recent years, many producers are returning to traditional technologies of cultivation of agricultural crops, and deep tillage, both with and without turnover of the layer, occupies one of the important places [1].

Deep loosening is used with soil-free tillage units in areas with high humidity and soil treatment is performed by flat-cut working bodies in areas subject to wind erosion. In other areas, it is more expedient to cultivate the soil with the layer turnover. So, according to scientists the main part of the roots of weeds and crop residues is in the layer of up to $10 \mathrm{~cm}$, the so-called mulching layer, partially observed accumulated nutrients is in the layer of $10-20 \mathrm{~cm}$, and such nutrients are at times more in layers of a deeper horizon. In this regard, dump ploughing is the only environmentally friendly way to deliver these elements to the upper layers of the soil, since this treatment moves the upper horizon to the bottom, and the lower, on the contrary, up. Natural favorable conditions are created for the growth of cultivated plants.

Preparing tillage units for operation consists of a set of sequential actions that

${ }^{*}$ Corresponding author: sergey_belousov_87@mail.ru 
include not only setting up and adjusting individual units and mechanisms of the arable unit, but also thorough preparation of the tillage unit [2].

As you know, the quality and traction resistance is affected by the preparation of all working bodies of the arable unit. Especially it is worth paying attention to the sharpening of details that directly undercut the soil layer. Many factors depend on the quality of sharpening of working bodies up to the traction resistance of the arable unit.

The sharpening of tillage working bodies and their interaction with the soil can be represented as a flat wedge, which is affected by various forces in size and direction that occur on its surface, the direction of which constantly changes during wear.

So the wear of the blade can be divided into several periods. By analyzing each of the periods, you can describe the degree and quality of interaction of the knife with the soil in detail.

Consider the first period, figure $1 \mathrm{a}, \mathrm{b}$, at this time the shape and size of the profile change, and only the size of the cutting profile changes after installing the form $[3,4]$.

According to the results of market analysis and prospective scientific researches, 2 types of blade, figure $1 \mathrm{a}, \mathrm{b}$, the profile of which (cutting edge, sharpening) is in the range of 0.1-0.2 mm are mainly used in tillage units. According to the researches of V. I. Vinogradov, K. A. Polevitsky and A. A. Knyazev, the process of merged soils cutting with the blade of this profile is accompanied by the formation of a compacted core, namely, the crumpling of the soil with a brake in the plastic zone and its failure after the formation of the path profile $\delta$.

The blade, figure $1 \mathrm{~b}$, in the thickness of the profile consists of a chamfer on the front side, since $\alpha_{0}=\geq 90^{\circ}-\varphi$ there is no sliding of soil particles when inserting the blade with such a profile. This fact indicates that a seal is formed, which leads to partial braking of the working body in this zone, and this in the complex of working elements of the plough affects the traction resistance of the entire plough unit.

Modern tillage units contain the so-called recoverable layer, which contributes to the self-sharpening of working bodies, this process occurs on dry soils especially good [5]. This is due to the fact that when processing dry soils, the interaction of the working body with the soil is more aggressive.

During wear, such a blade containing the hard-alloy surfacing takes the form of a profile, which is shown in figure 2 with a blade thickness $t$ equal to the projection of the section $A B$ of the parabola on the axis $Z$. When the blade is worn, which are shown in figure $1 \mathrm{a}, \mathrm{b}$, on soils with difficult conditions, the profile shown in figure 3 is obtained with a blade thickness $t_{3}$ equal to the projection of the occipital part of the chamfer $A D$ on the axis $Z$ [6]. When working on over-compacted soils, the blade will take the shape shown in figure 4 in which the thickness of the blade can be taken as a sum of $\mathrm{t}=\mathrm{t}_{3}+\mathrm{t}_{\pi}$ and projections of parabolas and $A C$ on the axis $\mathrm{Z}$. In turn, there is no sliding of particles in the $B C$ section due to the condition.

$$
\begin{aligned}
& \alpha_{0}=\geq 90^{\circ}-\varphi \\
& \alpha_{0}=\geq 90^{\circ}-\varphi
\end{aligned}
$$

At the same time, when the wedge is inserted into the soil, a seal is formed on the $C B$ section and particles slip on the $B K$ and $C D$ sections. The impact of the $B K$ section of the wedge (working body) contributes to the cracking and separation of the soil layer [7]. The $C D$ section compacts the furrow botton. This effect can be perceived as a negative factor that increases the traction resistance. 
Figure 6 shows the profile of the blade with stiffening ribs, this type of working bodies is often found on ploughs and cultivators of foreign companies. This working body is a thin blade with stiffening ribs. The thickness of the blade of this shape at a length of up to $50 \mathrm{~mm}$ is within the range of up to $2 \mathrm{~mm}$. Stiffeners up to $4 \mathrm{~mm}$ thick with an interval of up to $35 \mathrm{~mm}$ provide the necessary strength when working in various conditions, but not clogged with stones. The cross-section profile of a thin knife in figure 5 is similar to the blade profile shown in figure 4.

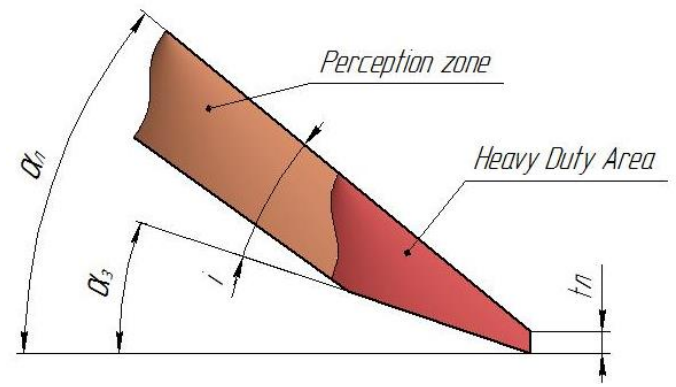

a

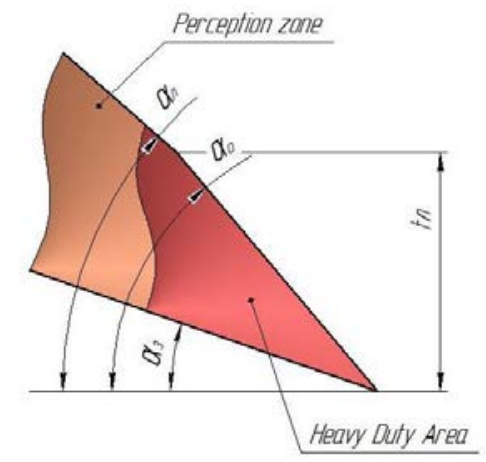

b

$a$ - new blade with a lower sharpening, $b$ - new blade with upper sharpening.

Fig. 1. Types of blades and their cutting edges

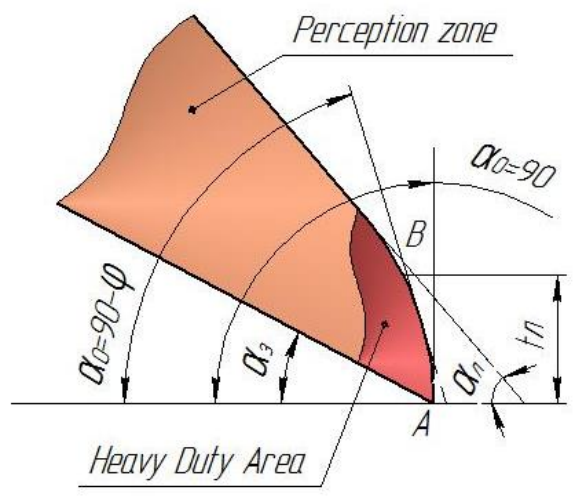

Fig. 2. Blade in the process of wear of the first order

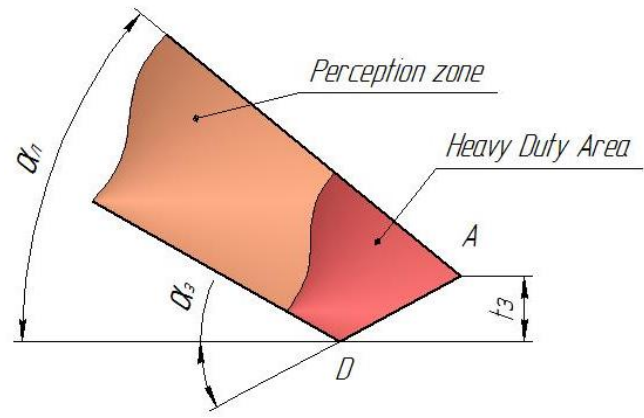

Fig. 3. Blade in the process of wear of the second order 


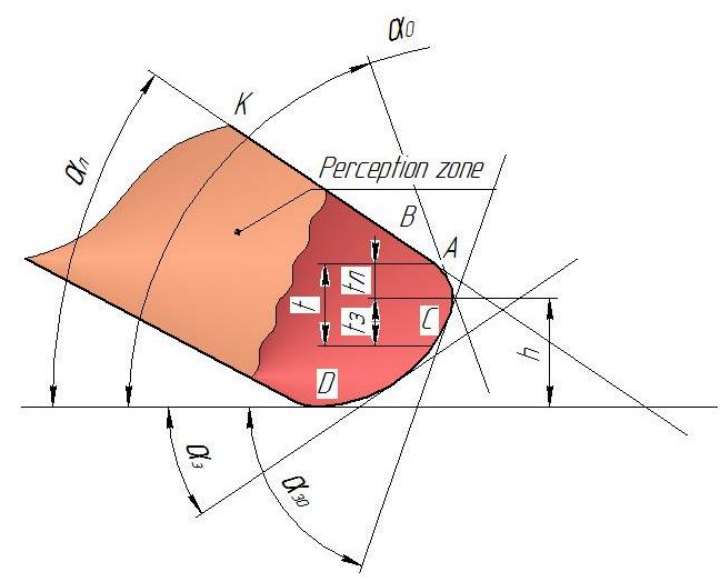

Fig. 4. Blade in the process of wear of the third order

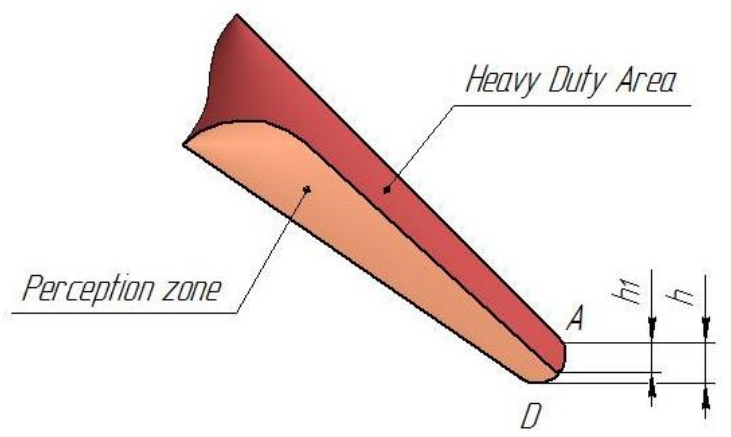

Fig. 5. Profile of the blade with edges

As can be seen from figure 6, the present profile of the working body on figure 6 $\mathrm{b}$, has the angle $\alpha_{o}$ with a smaller frontal angle of attack, in comparison with the similar attached working bodies in figure 6 a [8]. From the conducted theoretical researches and field tests, we get that this working body has a greater time to failure and takes longer to wear down to the first order of wear and then to the second respectively.

The theoretical researches show that the leading scientists recommend using a not very sharpened edge of the blade, as in the process of operation the sharpening $\alpha_{o}$ has a smaller thickness in comparison with the main working body, which do not have an additional angle of attack [9]. We also propose to introduce an additional angle of attack and, as a result, increase the frontal thickness of the sharpening profile. This will increase the sharpening area of the working body, and as a result, these working bodies will not wear out longer, and the cutting process and interaction with the soil will be more efficient. This will reduce the traction resistance of the arable unit. 


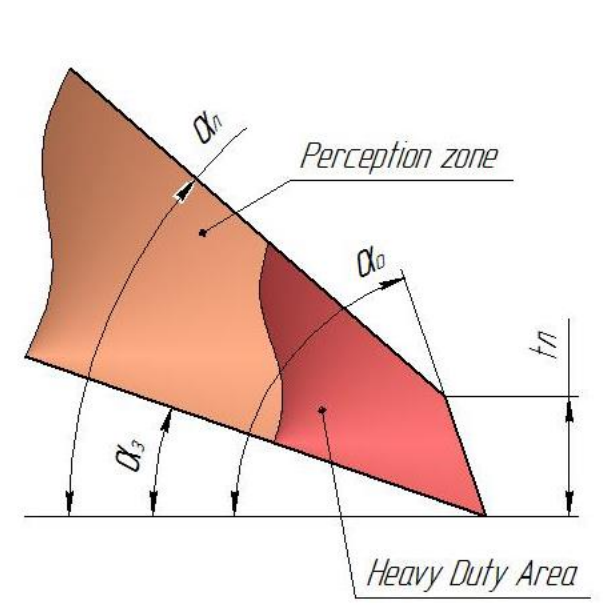

a

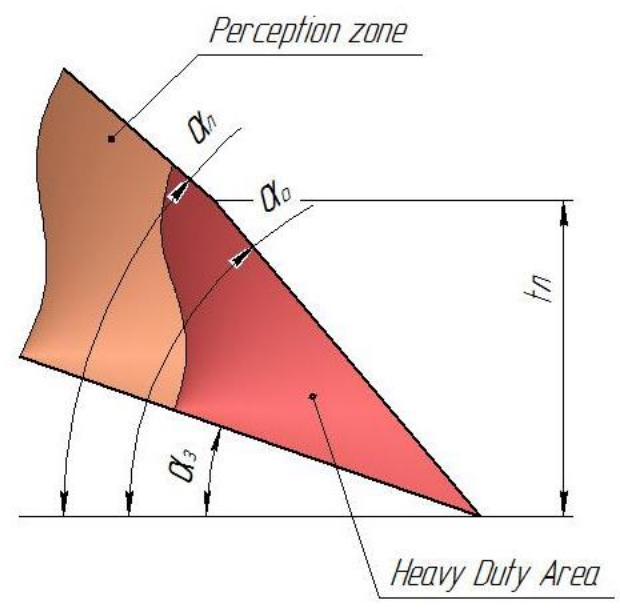

b

Fig. 6. Proposed profile of the blade.

This method of sharpening the working body has been implemented and tested in the fields on the design in figure 7 patent No. 191882 of December 06, 2019.

Fig. 7. Blade photo.

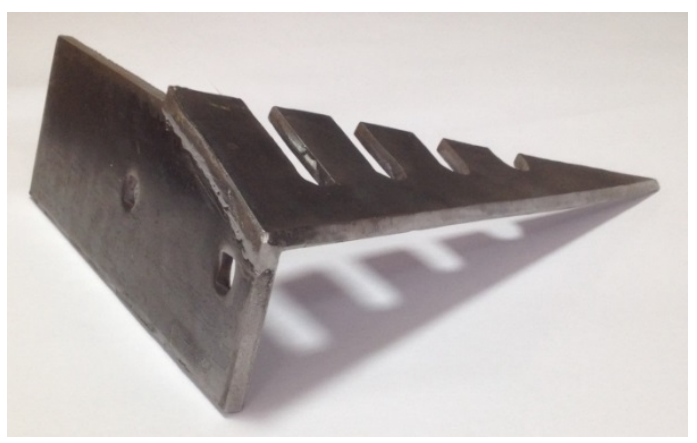

Based on the results of the work done, we can conclude: the angle of sharpening of the working body for layer-by-layer processing of the soil with the layer turnover is determined $[1,2,10]$. This working body can be used as a part of an arable unit for the main tillage treatment of soil with a layer turnover, and for non-tillage treatment. The obtained theoretical dependences of parameters and values can be used in further work on the study of parameters and dependencies of interaction of tillage working bodies, both for main and surface tillage.

\section{References}

1. Belousov S.V. Explanation of the angle of sharpening of a plough cutting working body Belousov S.V., Saprykin E.A., Karmazin I.S., E3S Web of Conferences 2019. C. 00025.

2. Belousov S.V. Design of the universal agricultural working body and study of its parameters Belousov S.V., Pomelyayko S.A., Novikov V.V., MATEC Web of Conferences 2018. C. 05006.

3. Belousov S.V. Theoretical justification of fruit separation process by a planetary fruit separator Belousov S.V., Gusak E.S., E3S Web of Conferences 2019. C. 00056. 
4. Bosoy E.S. Theory, construction and calculation of agricultural machines [Text] / E. S. Bosoy, I. I. Smirnov, O. V. Vernyaev, E. G. Sultan-Shah. - Moscow: "Engineering", $1978-568$ p.

5. Moiseev A.V. Experimental researches of determination of degree of interaction of a working organ with the object of treatment in plant growing Belousova A.I., Moiseev A.V., MATEC Web of Conferences 2018. C. 05001.

6. Goryachkin, V.P. Collection of ossions: in 3 t. / V.P. Goryachkin; by ed. action tsp VASHNIL prof. Dr. S.-H. Sciences ND Luchinsky. - 2nd ed. - M .: Kolos, 1968. - 455 p.

7. Pichugin, A.P. Moisture regime of leached chernozem under winter wheat, depending on its predecessor and method of increasing soil fertility / A.P. Pichugin // Grain farming. - 2008. - №1-2. - p.25-26.

8. Bogus A.E. Interaction of rotary working body of roller type with the object of processing Papusha S.K., Bogus A.E., Konovalov V.I. , MATEC Web of Conferences 2018. C. 05007.

9. Bogus A.E. Substantiation of the technological scheme of pneumatic grain seeder of subsurface dense sowing Bogus A.E., Kuzmenko A.D., E3S Web of Conferences 2019. C. 00040 .

10. Bogus A.E. The thrashed mass kinematic parameters establishment in the roller thrashing unit clearance Bogus A.E., Pusikova A.U., E3S Web of Conferences 2019. C. 00036 . 